\title{
Nrf2 expression modifies influenza A entry and replication in nasal epithelial cells ${ }^{\text {is }}$
}

\author{
Matthew J. Kesic ${ }^{\mathrm{a}, \mathrm{b}, *}$, Steven O. Simmons ${ }^{\mathrm{c}}$, Rebecca Bauer ${ }^{\mathrm{a}, \mathrm{b}}$, Ilona Jaspers ${ }^{\mathrm{a}, \mathrm{b}, \mathrm{d}}$ \\ a Curriculum in Toxicology, University of North Carolina at Chapel Hill, Chapel Hill, NC 27599-7127, USA \\ b Center for Environmental Medicine, Asthma, and Lung Biology, University of North Carolina at Chapel Hill, Chapel Hill, NC 27599-7127, USA

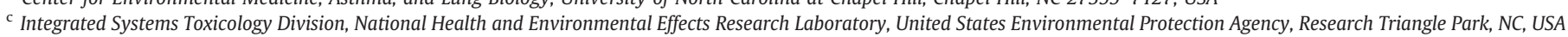 \\ d Department of Pediatrics, University of North Carolina at Chapel Hill, Chapel Hill, NC 27599-7127, USA
}

\section{A R T I C L E I N F O}

Article history:

Received 9 February 2011

Revised 7 April 2011

Accepted 13 April 2011

Available online 19 April 2011

\section{Keywords:}

Nrf2

Influenza

Nasal epithelial cells

Viral entry

\begin{abstract}
A B S T R A C T
Influenza infection is a major cause of morbidity and mortality worldwide, especially during pandemics outbreaks. Emerging data indicate that phase II antioxidant enzyme pathways could play a role in virusassociated inflammation and immune clearance. While Nrf2-dependent gene expression is known to modify inflammation, a mechanistic role in viral susceptibility and clearance has yet to be elucidated. Therefore, we utilized differentiated human nasal epithelial cells (NEC) and an enzymatic virus-like particle entry assay, to examine the role Nrf2-dependent gene expression has on viral entry and replication. Herein, lentiviral vectors that express Nrf2-specific short hairpin (sh)-RNA effectively decreased both Nrf2 mRNA and Nrf2 protein expression in transduced human NEC from healthy volunteers. Nrf2 knockdown correlated with a significant increase in influenza virus entry and replication. Conversely, supplementation with the potent Nrf2 activators sulforaphane (SFN) and epigallocatechin gallate (EGCG) significantly decreased viral entry and replication. The suppressive effects of EGCG on viral replication were abolished in cells with knocked-down Nrf2 expression, suggesting a causal relationship between the EGCG-induced activation of Nrf2 and the ability to protect against viral infection. Interestingly, the induction of Nrf2 via nutritional supplements SFN and EGCG increased antiviral mediators/responses: RIG-I, IFN- $\beta$, and MxA at baseline in the absence of infection. Our data indicate that there is an inverse relationship between the levels of Nrf2 expression and the viral entry/ replication. We also demonstrate that supplementation with Nrf2-activating antioxidants inhibits viral replication in human NEC, which may prove to be an attractive therapeutic intervention. Taken together, these data indicate potential mechanisms by which Nrf2-dependent gene expression regulates susceptibility to influenza in human epithelial cells.
\end{abstract}

(c) 2011 Elsevier Inc. All rights reserved.

\section{Introduction}

Influenza infection is a major cause of morbidity and mortality worldwide, especially during the recent $\mathrm{H} 1 \mathrm{~N} 1$ pandemic. In the United States alone, over 20,000 people die and over 100,000 individuals are hospitalized every year due to influenza virus-related diseases [1-3]. Influenza viruses cause annual epidemics and recurring pandemics with potentially severe consequences for global public health. Despite large-scale efforts in vaccination and antiviral therapies, the morbidity and mortality associated with influenza infections have not significantly changed in recent years [2-4].The

\footnotetext{
is The research described in this article has been reviewed by the National Health and Environmental Effects Research Laboratory, U.S. Environmental Protection Agency, and approved for publication. The contents of this article should not be construed to represent Agency policy nor does mention of trade names or commercial products constitute endorsement or recommendation for use.

* Corresponding author at: Center for Environmental Medicine, Asthma, and Lung Biology, Campus Box 7310, University of North Carolina at Chapel Hill, Chapel Hill, NC 27599-7310. Fax: + 19199666179 .

E-mail address: kesic@email.unc.edu (M.J. Kesic).
}

latest influenza pandemic was caused by the 2009 H1N1 virus and has thus far resulted in 42-86 million cases worldwide [5]. Epidemiologic studies show that high-risk groups including infants, elderly, and immune compromised individuals are more susceptible to influenza virus infections [6,7]. In the context of potentially pandemic respiratory viral infections, it is important to identify and protect susceptible subpopulations through identification of molecular targets/pathways for therapeutic intervention. Despite the large volumes of published data implicating age [1,7], preexisting diseases [8], nutritional deficiencies [9-11], and an impaired innate immune response [12-14] in influencing susceptibility to infection, the mechanism(s) for viral susceptibility are very complex and have yet to be elucidated.

Studies have shown that oxidative stress is associated with increased susceptibility and severity to respiratory viral infections, including influenza virus infections [14-17].There are a number of factors that may influence susceptibility to influenza infections in the human airway, specifically oxidant air pollutants, such as cigarette smoke, diesel exhaust, and ozone [18,19]. Oxidative stress is caused by an imbalance between the production of reactive oxygen species 
(ROS) and the body's ability to readily detoxify the reactive intermediates. Enzymes including phase II antioxidants, such as hemeoxygenase 1 (HO-1), are regulated by the transcription factor NF-E2-related factor 2 (Nrf2). The induction of these antioxidant enzymes can prevent or slow oxidative damage to cells. Emerging data indicate that Nrf2 plays an important role in the development of cancer, chronic lung diseases, and defense against oxidants, as well as host defense against respiratory viral infections [20-22]. Although it has been shown that oxidative stress increases the severity of viral infections, the exact mechanism as to how and why this happens and the role of Nrf2 in these responses are not fully understood.

Since airway epithelial cells are a major source of antioxidant enzyme production and the primary targets for influenza virus infection and replication, it is important to determine the role of cellular antioxidants in viral pathogenesis. On infection, epithelial cells respond by producing numerous cytokines, immunoregulatory molecules, and antiviral mediators, all components of the host innate immune response. One of the principal mediators of this response is type I interferons (IFN- $\alpha$ and IFN- $\beta$ ), which are secreted from virusinfected cells $[23,24]$ and are required to induce the synthesis and/or activity of mediators involved in turning off viral replication within the host cell. Although IFN- $\alpha / \beta$ act in an autocrine fashion to inhibit viral replication within the infected cell, it primarily functions in a paracrine mode by protecting neighboring cells that are not yet infected. The most potent stimuli for type I IFN synthesis are signals derived from a viral infection, specifically the recognition of doublestranded RNA that is produced by viruses during their replication process [25]. Another hallmark of influenza virus, is its sensitivity to the inhibitory effects of IFN-inducible MxGTPases (MxA), which significantly abrogates viral replication [26]. However, the role of Nrf2-dependent antioxidants in the modulation of the interferon/ antiviral response in epithelial cells has not been studied.

In this study, we used our established cell culture model of differentiated human nasal epithelial cells (NEC) [15] and generated lentiviral vectors that expresses Nrf2-specific short hairpin (sh)-RNAs to determine the role of Nrf2 in susceptibility to influenza A infection. We show that Nrf2-specific shRNA effectively decreased both Nrf2 mRNA and Nrf2 protein expression in these cells, which correlated with significantly increased viral entry and replication in transduced human NECs. Importantly, we directly show an inverse relationship between levels of Nrf2 expression and susceptibility to viral infection. Interestingly, we demonstrate that enhancing Nrf2 expression via supplementation with sulforaphane (SFN) and epigallocatechin gallate (EGCG) increased antiviral mediators in the absence of viral infection and also abrogated viral entry. Taken together, our data are consistent with the conclusion that Nrf2-dependent gene expression is an important modifier of susceptibility to influenza.

\section{Materials and methods}

Nasal epithelial cell cultures, cell lines, and growth conditions

Primary human NECs were obtained as previously described [16]. Briefly, NECs were obtained from healthy adult volunteers by gently stroking the inferior surface of the turbinate several times with a Rhino-Probe curette (Arlington Scientific, Arlington, TX), which was inserted through a nasoscope. The selection criteria for recruitment of subjects was similar to those described previously [27]. This protocol was approved by the University of North Carolina School of Medicine Institutional Review Board for Biomedical Research. Primary human nasal epithelial cells were expanded to passage 2 in bronchial epithelial growth medium (BEGM, Cambrex Bioscience Walkersville, Inc., Walkersville, MD) and then plated on collagen-coated filter supports with a $0.4 \mu \mathrm{m}$ pore size (Trans-CLR; Costar, Cambridge, MA) and cultured in a 1:1 mixture of bronchial epithelial cell basic medium (BEBM) and DMEM-H with SingleQuot supplements (Cambrex), bovine pituitary extracts $(13 \mathrm{mg} / \mathrm{ml})$, bovine serum albumin (BSA, $1.5 \mu \mathrm{g} / \mathrm{ml}$ ), and nystatin (20 units). On confluency, all-trans retinoic acid was added to the medium to establish air liquid interface (ALI) culture conditions (removal of the apical medium) to promote differentiation. Mucociliary differentiation was achieved after 18-21 days post-ALI.

The HEK293T cell line was purchased from GenHunter (Nashville, TN). Cells were cultured in Dulbecco's modified Eagle's medium (DMEM) supplemented with $10 \%$ fetal bovine serum (FBS, Atlanta Biologicals, Lawrenceville, GA) and penicillin-streptomycin (HyClone; Waltham, MA) at $37{ }^{\circ} \mathrm{C}$ in a humidified $5 \% \mathrm{CO} 2$ atmosphere. The BEAS-2B cell line was derived by transforming human bronchial cells with an adenovirus 12 -simian virus 40 construct [28]. We obtained our BEAS-2B cells from the American Type Culture Collection (ATCC, Manassas, VA). BEAS-2B cells were grown in keratinocyte basal medium (KBM) supplemented with $30 \mu \mathrm{g} / \mathrm{ml}$ bovine pituitary extract, $5 \mathrm{ng} / \mathrm{ml}$ human epidermal growth factor, $500 \mathrm{ng} / \mathrm{ml}$ hydrocortisone, $0.1 \mathrm{mM}$ ethanolamine, $0.1 \mathrm{mM}$ phosphoethanolamine, and $5 \mathrm{ng} / \mathrm{ml}$ insulin.

\section{Virus-like particle (VLP) entry assay}

\section{Construction of VLP expression plasmids}

To generate the $\beta$-lactamase-M1 fusion expression plasmid (pCAGGS- $\beta$-lacM1 PR8) the influenza A/Puerto Rico/8/34/Mount Sinai (H1N1) M1 sequence was PCR-amplified from the M1 expression vector pDZ-M (which was kindly provided by Dr. Adolfo Garcia-Sastre, Mount Sinai School of Medicine) and inserted into the pCAGGS vector [29-31]. The $\beta$-lactamase gene was PCR-amplified from pcDNA3.1 and fused $\mathrm{N}$-terminally to M1 within pCAGGS to create a modified $\beta$-lactamaseM1 fusion. In the modified $\beta$-lactamase, the first 24 amino acids were excluded to remove a secretion signal and His 24 was substituted with Asp to create an optimal Kozak consensus sequence. The pcDNA3.1- $\beta$-lactamase construct has been described previously [32]. The influenza A/Puerto Rico/8/34/Mount Sinai (H1N1) HA (pCAGGS-HA) and NA ( $\mathrm{pDZ}-\mathrm{NA}$ ) overexpression vectors were generously provided by Dr. Aldolfo Garcia-Sastre and have been described previously [29-31,33].

\section{Production of VLPS}

To generate influenza A/PR/8/ H1N1 $\beta$-lactamaseM1VLPs (PR8 $\beta$-lacM1 VLPs), 293T cells were cotransfected with $3 \mu \mathrm{g}$ each of pCAGGS-HA, pDZ-NA, and pCAGGS- $\beta$-lacM1 PR8 using FuGENE HD (Roche Applied Science, Indianapolis, IN) according to the manufacturer's instructions. The supernatant containing the VLPs was collect $48 \mathrm{~h}$ posttransfection and clarified of floating cell debris by centrifugation at $3000 \mathrm{rpm}$ for $10 \mathrm{~min}$. The VLPs were concentrated once by low-speed centrifugation through an Amicon Ultra $100 \mathrm{kD}$ centrifuge filter unit (Millipore; Billerica, MA), and the retentates were aliquoted and stored at $-80^{\circ} \mathrm{C}$.

\section{VLP entry assay}

Target cells (BEAS-2B) were seeded in either 96-well plates or chamber slides (Lab-Tek Chamber slides, Nalge Nunc International, Naperville, IL). After $24 \mathrm{~h}$, cells were washed with HBSS and VLPs were added in a total volume of $100 \mu$ for 96 -well format or $400 \mu$ volume for chamber slides. Cells were incubated at $37^{\circ} \mathrm{C}$ for $3 \mathrm{~h}$. The cells were washed twice with HBSS to remove unbound virus and infected cells were detected by using GeneBLAzer FRET in vivo cell-based assay system substrate CCF2-AM according to the manufacturer's recommendations (Invitrogen). Infected cells were visualized using a Nikon C1Si laser scanning confocal microscope using suggested excitation and emission filter settings and images were processed using the EZ-C1 FreeViewer software (Nikon Instruments, Melville, NY), or quantified by using the POLARstar OPTIMA plate reader (BMG LABTECH, Inc.). To determine the effects of Nrf2 on viral entry, modulation of Nrf2 expression was achieved by transfecting $1 \mu \mathrm{g}$ of either a CMV-driven human Nrf2 expression plasmid or the LV-Nrf2 lentiviral vector using 
FuGENE HD (Roche Applied Science, Indianapolis, IN) according to the manufacturer's instructions $24 \mathrm{~h}$ prior to VLP entry assay. Similarly, endogenous Nrf2 expression was induced via supplementation with $1 \mu \mathrm{M}$ of either SFN (Sigma-Aldrich, St. Louis, MO) or EGCG (SigmaAldrich) $3 \mathrm{~h}$ prior to performing the entry assay.

\section{Infection with influenza}

For all experiments we used influenza A/Bangkok/1/79 (H3N2 serotype) which was propagated in 10-day-old embryonated hen's eggs. The virus was collected in the allantoic fluid and titered by $50 \%$ tissue culture infectious dose in Madin-Darby canine kidney cells and hemagglutination as described before [34]. Stock virus was aliquoted and stored at $-80{ }^{\circ} \mathrm{C}$ until use. Unless otherwise indicated, for infection about $5 \times 10^{5}$ cells were infected with approximately 128 hemagglutination units (HAU) of influenza A Bangkok 1/79, which resulted in approximately $10 \%$ of the cells being infected with influenza $24 \mathrm{~h}$ postinfection. Total RNA, total protein, basolateral supernatants, and apical washes were collected $24 \mathrm{~h}$ postinfection.

\section{Influenza virus titer}

Influenza virus titers in apical washes were determined by $50 \%$ tissue-culture infectious dose (TCID50) in Madin Darby canine kidney (MDCK) cells and evaluated using agglutination of red blood cells as an indicator according to a modified protocol described before [35]. Briefly, MDCK cells grown in round-bottom 96-well plates were inoculated with virus-containing samples diluted in serum-free MEM containing $20 \mu \mathrm{g} / \mathrm{ml}$ trypsin using $\log 10$ dilutions. After 3 days incubation a suspension of human erythrocytes $(0.5 \%)$ was added to each well. Wells exhibiting hemagglutination were considered positive and virus titers were expressed as $\log \operatorname{TCID}_{50}$.

\section{Western blotting}

Cell lysates were prepared at $24 \mathrm{~h}$ postinfection in Passive lysis buffer (Promega, Madison, WI) with a protease inhibitor mixture (Cocktail Set III; Calbiochem, San Diego, CA) as well as phosphatase inhibitors $\left(0.5 \mathrm{mM} \mathrm{NaVO}_{4}, 1 \mathrm{mM} \beta\right.$-glycerophosphate) on ice for $30 \mathrm{~min}$. After centrifugation, total protein concentrations were determined by the Bradford protein assay (Bio-Rad). The cell lysates were subjected to $12 \%$ sodium dodecyl sulfate-polyacrylamide gel electrophoresis (SDS-PAGE) and transferred to nitrocellulose (Schleicher \& Schuell Biosciences, Keene, NH). Proteins were detected using specific antibodies to Nrf2 (1:1000; Santa Cruz Biotechnology, Santa Cruz, CA), HO-1 (1:1000; Enzo Life Sciences, Plymouth Meeting, PA), or $\beta$-actin (1:2000; US Biological, Swampscott, MA), and used as a loading control. Antigen-antibody complexes were stained with anti-rabbit or antimouse, horseradish peroxidase (HRP)-conjugated antibody (1:2000, Santa Cruz Biotechnology) and detected with SuperSignal West Pico chemiluminescent substrate (Pierce, Rockford, IL).

\section{shRNA constructs}

shRNA hairpin oligonucleotides shown below were designed by selecting an 18-bp site from the human NFE2L2 complete mRNA (NCBI Reference Sequence: NM_006164.3) optimized for siRNA targeting of the NFE2L2 mRNA (LV-Nrf2) or a random 18-bp sequence (LV-scramble) with no predicted homology to human genomic or transcript sequence:

\section{LV-Nrf2, 5'-TCAA A T CCATGTCCTGCT-3';}

LV-scramble, 5'-ACTCTCGCCCAAGCGAGA-3'.

Single-stranded synthetic 97-bp oligonucleotides (Invitrogen Corp., Valcencia, CA) incorporating the sense/antisense sequences in a stem-loop motif were PCR-amplified using the primers forward,
5'-AGTCACTCGAGTGCTGTTGACAGTGAG-3'; and reverse, 5'-AAGTCAGGATCCTCCGAGGCAGTAGG-3.' The resulting shRNA PCR products were subcloned into a modified lentiviral transfer vector, GIPZ (Thermo Fisher Scientific Inc., Birmingham, AL) between the XhoI and the BamHI sites and the constructs were verified by fluorescent DNA capillary sequencing. This cloning strategy nests the shRNA fragments between $5^{\prime}$ and $3^{\prime}$ miRNA30 adaptors within the $3^{\prime}$ untranslated region of a green fluorescent protein (GFP) reporter gene under the control of a $C M V$ promoter.

\section{Transduction of cells with lentivirus}

BEAS-2B cells were seeded in a 12-well plate in KGM media. At $24 \mathrm{~h}$ postseeding, media were replaced with serum-free media and cells were infected with the lentivirus at a multiplicity of infection (MOI) of 10 to ensure efficient infection. At $6 \mathrm{~h}$ postinfection complete media were added, and cells were incubated overnight. Infection for NECs was performed similarly, with a few modifications. Briefly, NECs were infected from the apical side at an MOI of 10 and were incubated overnight while complete media remained unchanged on the basallateral side. At $24 \mathrm{~h}$ postinfection, the virus was removed from the apical surface reestablishing ALI conditions.

\section{Lentiviral vector production and titering}

HEK293T cells were cotransfected in $10 \mathrm{~cm}$ dishes with purified LV-scramble or LV-Nrf2 transfer vector plasmids and lentiviral packing mix (Open Biosystems; Huntsville, $\mathrm{AL}$ ) according to the manufacturer's instructions. At $16 \mathrm{~h}$ posttransfection, cell culture medium was replaced with $12 \mathrm{ml}$ fresh DMEM and cells were incubated for an additional $48 \mathrm{~h}$ at $37^{\circ} \mathrm{C}$. Medium was then harvested and detached cells were pelleted by centrifugation for $10 \mathrm{~min}$ at $5000 \mathrm{~g}$. The resulting supernatants from the individual transfections were concentrated once by low-speed centrifugation through an Amicon Ultra 100-kDa centrifuge filter unit (Millipore; Billerica, MA), and the retentates were aliquoted and stored at $-80^{\circ} \mathrm{C}$. To determine viral titers, 50,000 HEK293T cells stably expressing the TetOff (rtTA3; Clontech, Mountain View, CA) transactivator were transduced with $50 \mu \mathrm{l}$ of lentiviral stock dilutions ranging from 1:10 to 1:781,250. Viral titers were determined $96 \mathrm{~h}$ posttransduction by counting green fluorescent colonies (encoded by the vector) by fluorescent microscopy and multiplying the colony count by the dilution and volume factors.

\section{RT-PCR}

Total RNA was extracted using TRizol (Invitrogen) according to the supplier's instruction. First-strand cDNA synthesis and real-time RT-PCR were performed as described previously [15,34] using commercially available primers and probes for HA, RIG-I, IFN- $\beta$, and MxA (inventoried Taqman Gene Expression Assays) purchased from Applied Biosystems (Foster City, CA). Nrf2 primers and probe were previously described [36].

\section{Fluorescent microscopy}

For fluorescent analysis of the GFP reporter to identify lentiviral transduced cells, fluorescence was visualized by a Nikon C1Si laser scanning confocal microscope using the suggested excitation and emission filter settings and images were processed using the EZ-C1 FreeViewer software (Nikon Instruments, Melville, NY). To view $\beta$-lactamase activity in the virus entry assay, fluorescence was visualized by Nikon C1Si laser scanning confocal microscope using the suggested excitation and emission filter settings and images were processed using the EZ-C1 FreeViewer software. Equal adjustments were performed on all images to achieve maximum clarity. 


\section{Results}

shRNA lentivirus-mediated knockdown of Nrf2 mRNA and Nrf2 protein expression in NEC

$\mathrm{Nrf} 2$ is the master transcriptional regulator of the phase II antioxidant pathways during oxidative stress. To determine the role Nrf2 plays in susceptibility to influenza, we utilized a lentiviral vector that expressed Nrf2-specific shRNA (LV-Nrf2) to effectively decrease both Nrf2 mRNA and Nrf2 protein expression in transduced human differentiated NECs from healthy volunteers, while a separate vector expressing a scrambled nonspecific sequence was used as a negative control. To determine the ability of the lentivirus to transduce differentiated NECs, we infected at a multiplicity of infection of 10 and analyzed the cells for the presence of GFP expression (encoded by the same transcript as the shRNA) $48 \mathrm{~h}$ postinfection (Fig. 1A). Efficiency of the lentivirus to knock down Nrf2 gene expression was measured by isolating total RNA from transduced cells and utilizing real-time RT-PCR to quantitate Nrf2 mRNA transcripts normalized to cellular $\beta$-actin expression. Nrf2 mRNA expression was significantly knocked down by lentivirus LV-Nrf2 as compared to the control lentivirus (LV-scramble) (Fig. 1B). Western blot analysis further confirmed that the expression of Nrf2 protein as well as HO-1, an Nrf2-dependent gene, was reduced, which correlated with the Nrf2 mRNA suppression (Fig. 1C).

\section{Suppression of Nrf2 gene expression enhances influenza virus replication}

Next we wanted to evaluate how suppression of NRF2 affects viral replication. Cells were infected with influenza A/Bangkok/1/79 $48 \mathrm{~h}$ posttransduction with the lentiviral vectors (LV-scrambled and LV-Nrf2). Total RNA was subjected to real-time RT-PCR to quantitate the influenza viral hemagglutinin transcript (HA) (Fig. 2A). As depicted, we saw a significant increase in the amount of viral $H A$ mRNA produced in the cells when Nrf2 is knocked down as compared to our control. Similarly, by analyzing the apical washes for influenza viral titers, we again saw a significant increase in viral replication in cells with suppressed Nrf2 expression as compared to the control (Fig. 2B). To validate the suppression of Nrf2 at the time of viral infection, cellular lysates were used to analyze protein levels of both Nrf2 and HO-1 (Fig. 2C). Western blot analysis showed that expression levels of both Nrf2 and HO-1 were significantly reduced both pre- and postinfluenza infection. These results demonstrate that knockdown of Nrf2 significantly increased viral replication in NECs.

\section{Induction of Nrf2 via supplementation suppresses viral replication}

Previous reports have shown that Nrf2 gene expression can be induced via antioxidant supplementation [37,38], more specifically by the addition of a polyphenolic catechin, epigallocatechin-3gallate, or the organosulfur compound sulforaphane. Both compounds have the ability to induce Nrf2 gene expression. Based on initial dosing studies, we determined that a concentration of 1 and $10 \mu \mathrm{M}$ is sufficient to detect effects of SFN and EGCG on Nrf2dependent gene expression in NECs in vitro with $10 \mu \mathrm{M}$ causing cytotoxicity (data not shown). Therefore, NECs were treated with $1 \mu \mathrm{M}$ of either SFN or EGCG $3 \mathrm{~h}$ prior to infection with influenza virus. To explore the effects of these antioxidant compounds on viral replication, total RNA was isolated and resulting cDNAs were quantified by RT-PCR to measure the levels of influenza $H A$ transcripts present. As shown in Fig. 3A, both SFN and EGCG inhibit viral replication as marked by decreased $H A$ gene expression. We again collected apical washes to perform viral titer assays. Our results show that EGCG significantly reduced viral replication, while SFN had minimal affects (Fig. 3B).Western blots revealed that the addition of SFN and EGCG did increase the protein levels of Nrf2 and HO-1, with EGCG enhancing Nrf2 expression (approximately 3fold) as compared to the vehicle (Fig. 3C). Taken together, these

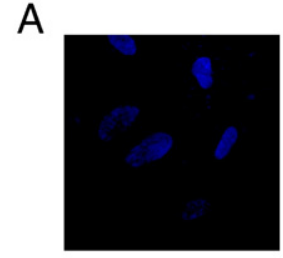

DAPI

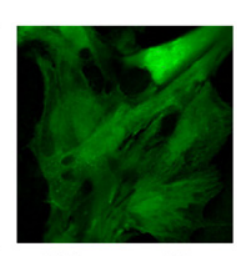

LV-scramble (GFP)

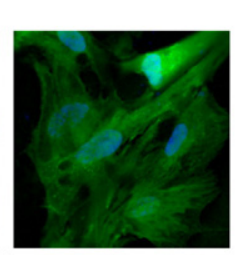

Overlay
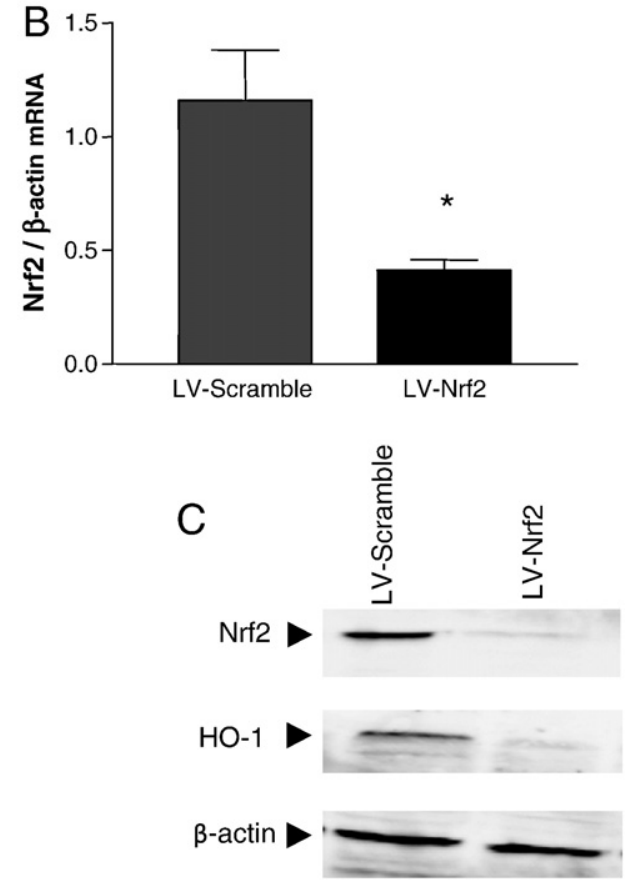

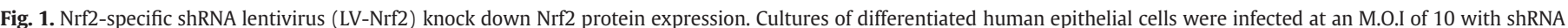

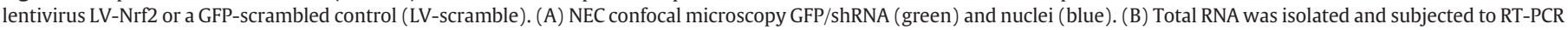

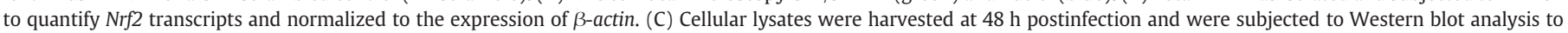
detect Nrf2, HO-1, and $\beta$-actin. $\beta$-Actin levels were used as internal loading controls. 

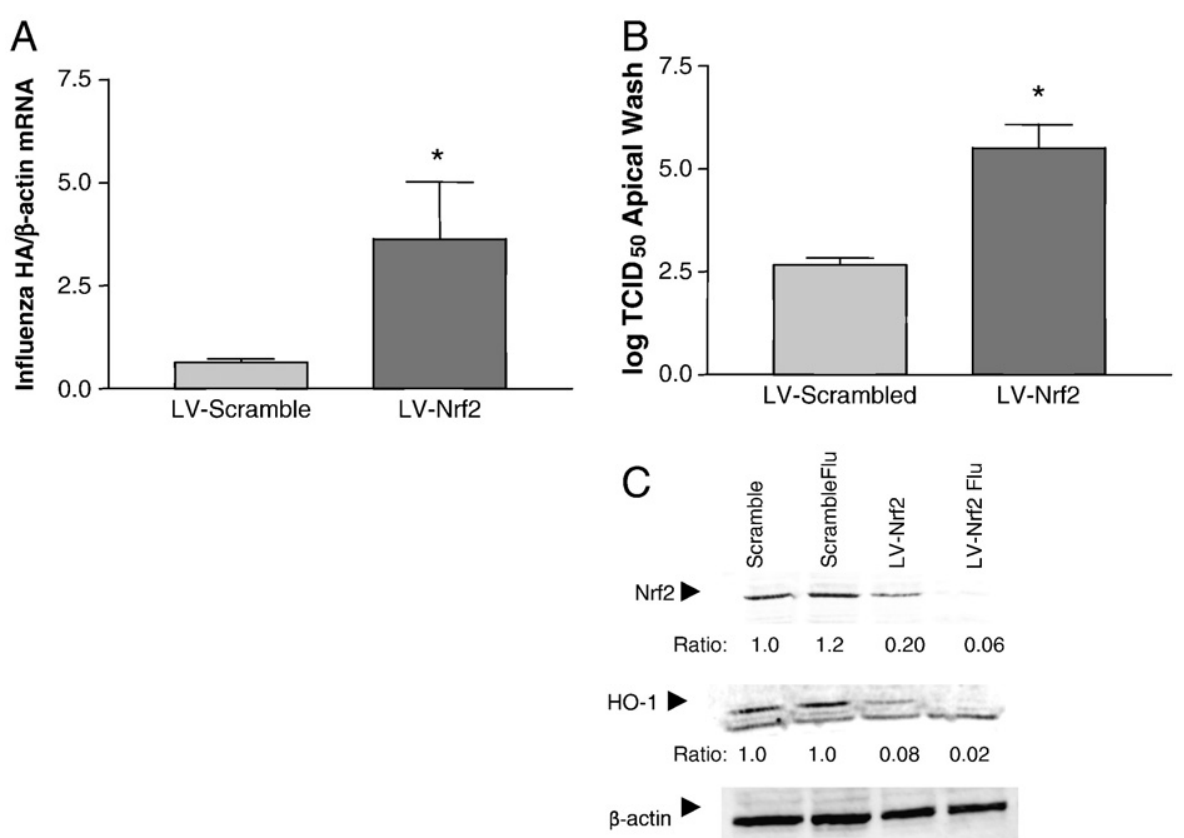

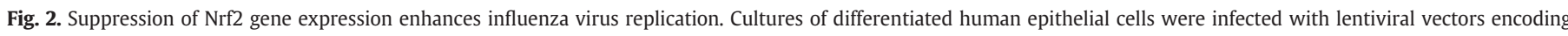

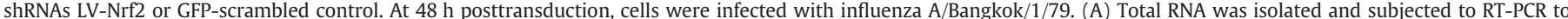

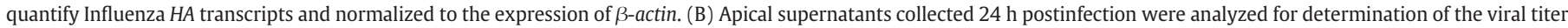

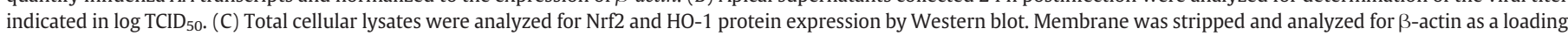

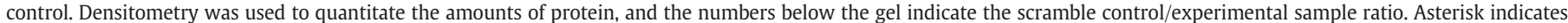
statistical significance between test sample and control, ${ }^{*} P<0.05$.

results indicate that induction of Nrf2 via antioxidant supplementation suppresses influenza virus replication in NECs. To determine whether the effects of EGCG on replication are indeed mediated by Nrf2, we performed experiments whereby NECs were transduced with either LV-Nrf2 or LV-scramble prior to treatment with EGCG.

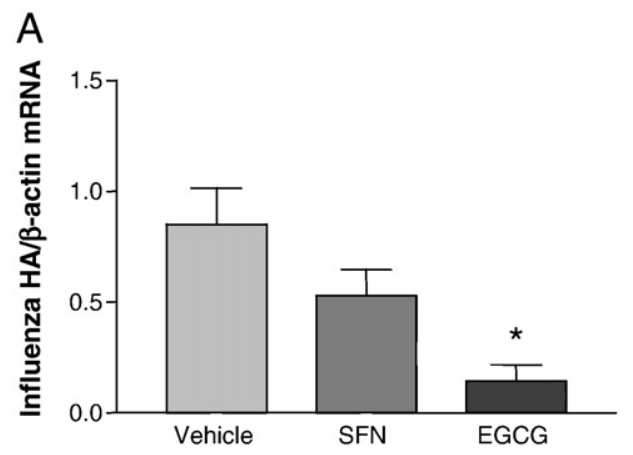

Fig. 4 shows that there is an Nrf2-dependent effect. The suppressive effects of EGCG on viral replication were eliminated in cells with knocked-down Nrf2 expression, suggesting a causal relationship between the EGCG-induced activation of $\mathrm{Nrf} 2$ and the ability to protect against viral replication.

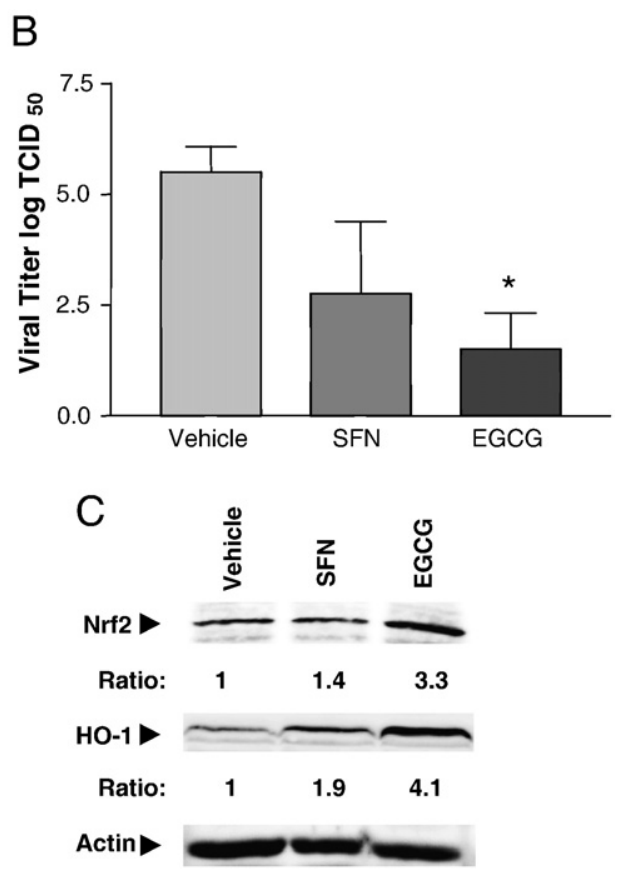

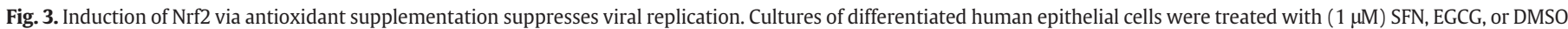

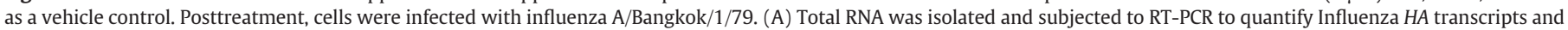

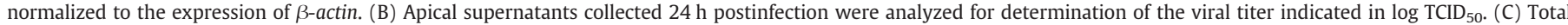

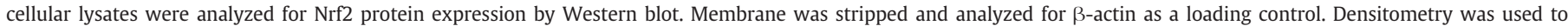

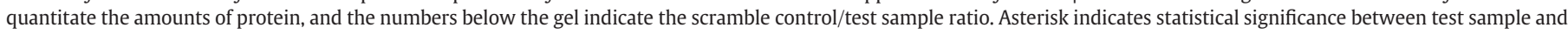
control, ${ }^{*} P<0.05$. 


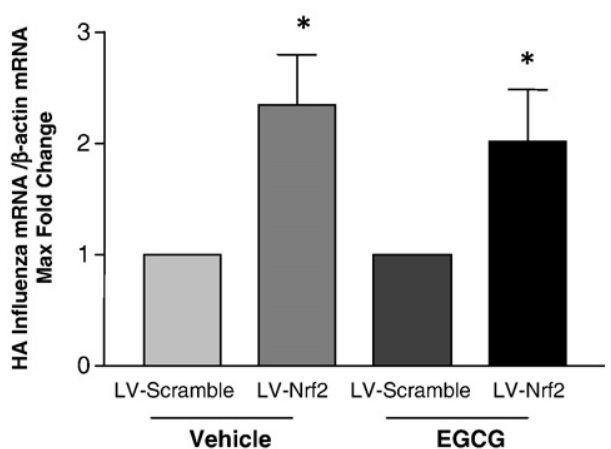

Fig. 4. Effects of EGCG are dependent on Nrf2. NECs were transduced with Nrf2-shRNA lentivirus (LV-Nrf2) or the scrambled control (LV-scramble). $48 \mathrm{~h}$ posttransduction, cells were supplemented with $1 \mu \mathrm{M}$ EGCG prior to influenza infection. Total RNA was isolated and subjected to RT-PCR to quantify Influenza HA transcripts and normalized to the expression of $\beta$-actin. Asterisk indicates statistical significance between test sample and control, ${ }^{*} P<0.05$.

Antioxidant supplementation modulates innate antiviral defense responses, protecting the cells from viral infection

To determine the potential mechanisms mediating the suppression of viral replication due to antioxidant pretreatment, we assessed whether the innate antiviral immune response mediators were modulated. Specifically, we analyzed the expression of interferon- $\beta$ $(I F N-\beta)$, retinoic acid inducible gene I (RIG-I), and the interferoninduced human MxA. NECs were treated with either SFN or EGCG as stated above. Total RNA was isolated and RT-PCR was performed to quantitate the amount of each cellular transcript independent of influenza infection. Interestingly, we show that antioxidant supplementation, specifically with EGCG, significantly increases the mRNA expression levels of all three antiviral genes as compared to the vehicle alone (Figs. $5 \mathrm{~A}-\mathrm{C}$ ). These data demonstrate that, even in the absence or prior to viral infection, addition of SFN and EGCG significantly increases antiviral mediator expression.

Nrf2 gene expression modulates influenza virus entry

To decipher which step(s) in the virus life cycle are affected by Nrf2 activity, we developed an enzymatic virus-like particle assay, similar to previous reports [39]. For these experiments we utilized the well-characterized BEAS-2B cells line. BEAS-2B cells were infected with a virus-like particle that only expresses the hemagglutinin (HA), neuraminidase (NA), and matrix $(\mathrm{M})$ proteins along with a functional $\beta$-lactamase reporter fusion (PR8 $\beta$-lacM1 VLP) prior to loading with the fluorogenic substrate CCF2-AM. Fig. 6A shows the microscopy of live cells in which the PR8 $\beta$-lacM1 VLP has entered the cells and cleaved the CCF2-AM substrate (green), disrupting FRET, resulting in CCF2 emission at $447 \mathrm{~nm}$ (blue), demonstrating the feasibility of this assay. To determine the effects of Nrf2 expression levels on virus entry, BEAS-2B cells were transfected with either the LV-Nrf2 lentiviral vector to knockdown Nrf2 expression or a CMV-driven Nrf2 overexpression cDNA plasmid (CMV-Nrf2). The results show that the suppression of Nrf2 results in a significant increase in viral entry, but that entry can be blocked by overexpression of Nrf2 (Fig. 6B). Finally we wanted to verify if antioxidant supplementation was involved with the entry portion of the virus life cycle. Again, BEAS-2B cells were pretreated with either SFN or EGCG prior to the infection with the PR8 $\beta$-lacM1 VLP. As shown in Fig. 6C, antioxidant supplementation significantly decreases viral entry. These data confirm that cellular expression levels of Nrf2 play a role in viral replication and that one mode of action is reduced viral entry.

\section{Discussion}

The exact role of oxidative stress in viral replication and/or pathogenesis remains to be fully defined. Because airway epithelial cells are not only a major source of antioxidant enzymes and defense mediators in the lung but also the primary targets for influenza

\section{A}

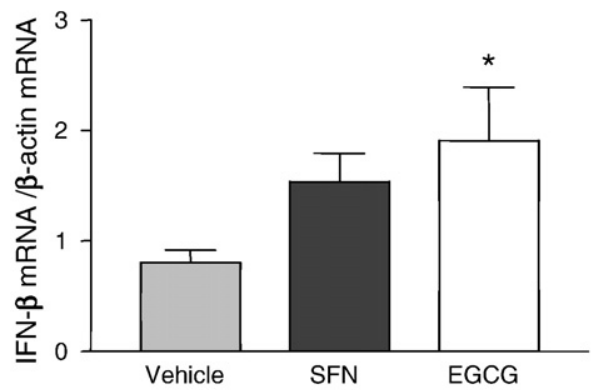

B

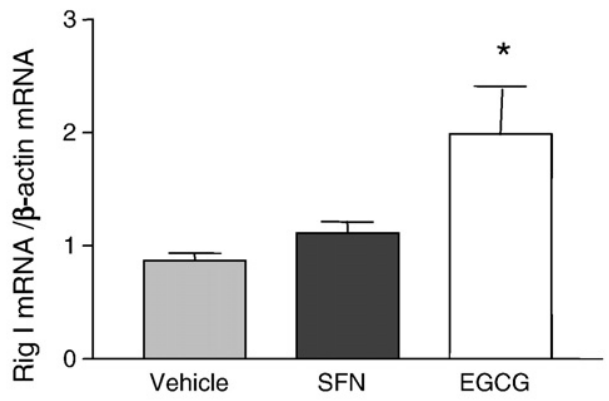

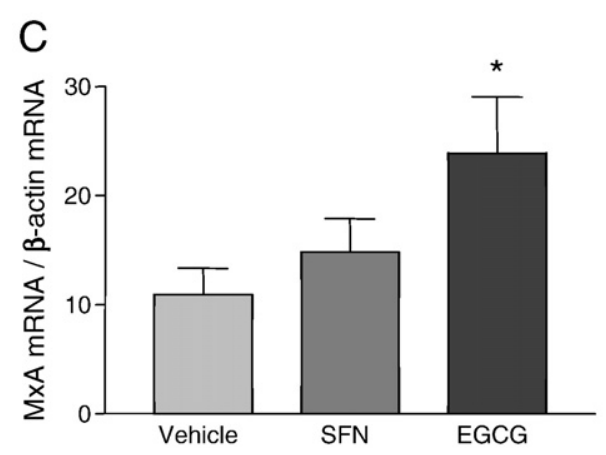

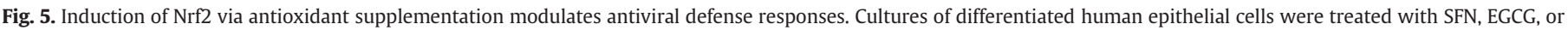

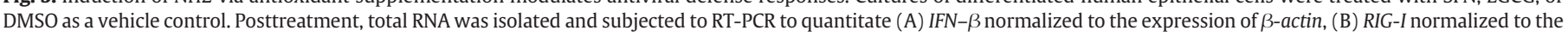
expression of $\beta$-actin, (C) $M x A$ transcripts normalized to the expression of $\beta$-actin. Asterisk indicates statistical significance between test sample and control, * $P<0.05$. 

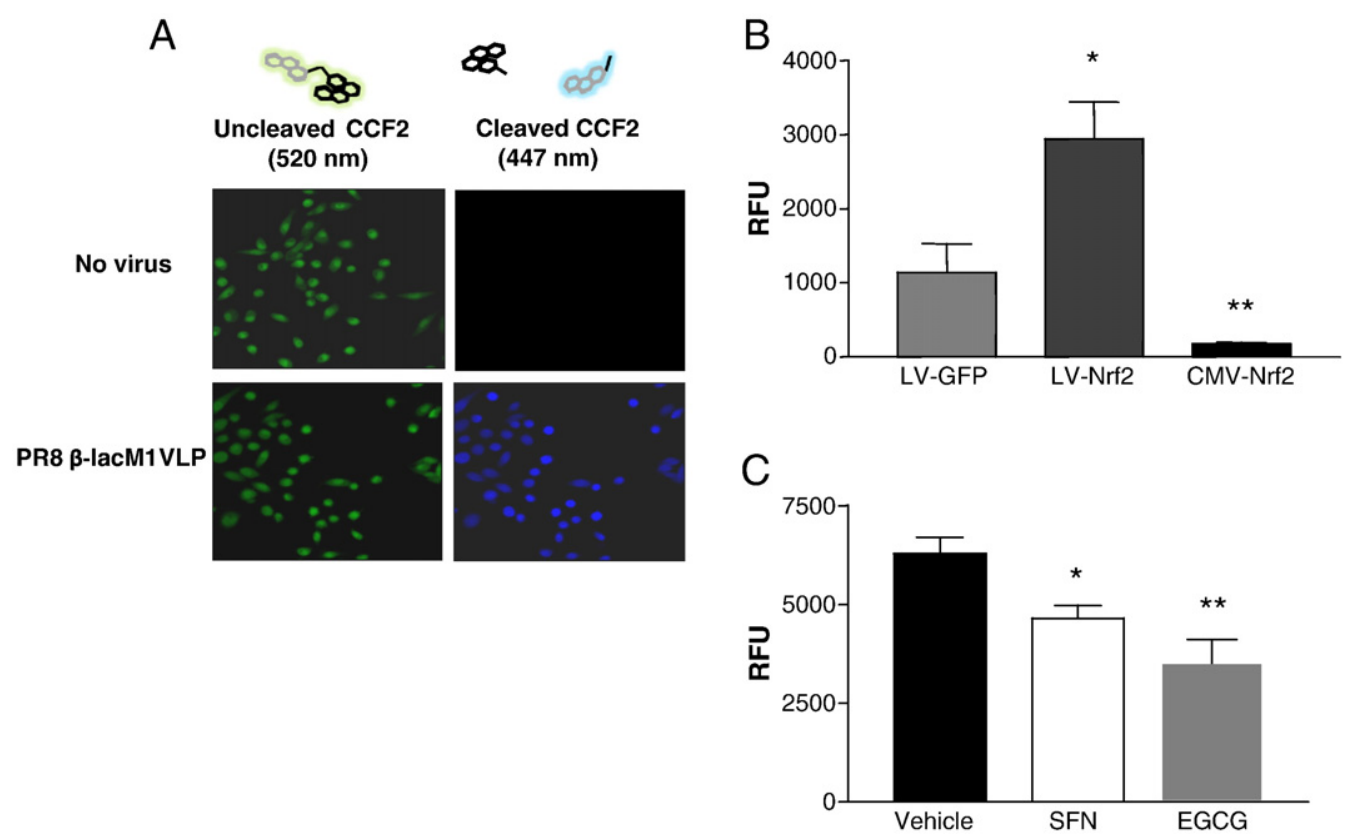

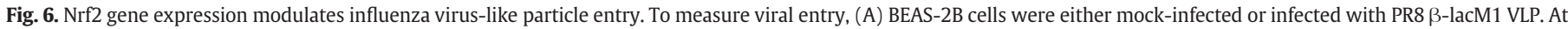

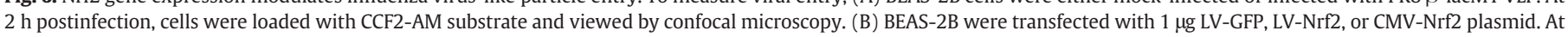

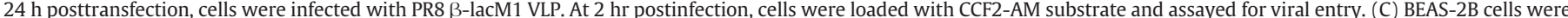

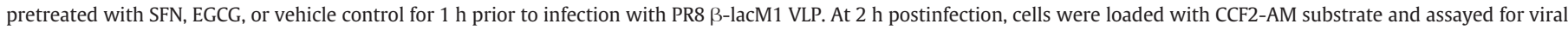
entry. Asterisk indicates statistical significance between test sample and control, ${ }^{*} P<0.05$.

infection, it is important to determine the role of cellular antioxidant mechanisms in viral pathogenesis. Nrf2 is a multifunctional transcription factor that plays a role in chronic lung diseases and defense against oxidants, as well as host defense against respiratory viral infections [20,40-42]. Although it has been shown that oxidative stress increases viral infection and antioxidants are thought to be protective against influenza, the exact mechanism as to how and why this happens and the role of Nrf2 in these responses have yet to be elucidated. Using genetic and pharmacological manipulation of $\mathrm{Nrf2}$ gene expression, our results demonstrate that in human epithelial cells, Nrf2-dependent gene expression regulates susceptibility to influenza at the level of antiviral mediator expression and viral entry.

The goal of this study was to understand the role Nrf2 gene expression plays in regulating susceptibility to respiratory virus infections, such as influenza, in fully differentiated human primary nasal epithelial cells. Previous studies have shown that $\mathrm{Nrf2}^{-} \mathrm{I}^{-}$mice developed enhanced virus-induced inflammatory and mucus cell metaplastic changes and demonstrated decreased viral clearance after infection with respiratory syncytial virus (RSV), while pretreatment of $\mathrm{Nrf2}^{-} /^{+}$or $\mathrm{Nrf2}^{-} /^{-}$mice with a potent $\mathrm{Nrf2-activating} \mathrm{agent} \mathrm{sulfo-}$ raphane (SFN) resulted in increased levels of antioxidants including heme oxygenase, improved viral clearance, and reduced virusassociated inflammation [17,43]. While these studies showed a clear association between reduced Nrf2 expression and enhanced susceptibility to respiratory virus infections in mice in vivo, the cell types and mechanisms mediating these effects remained unclear. Utilizing human differentiated NECs transduced to express shRNAs targeting Nrf2, our data show that Nrf2 gene expression plays a protective role against influenza virus at the level of the epithelium. Specifically, our data show that Nrf2 expression affects influenza virus entry and replication in epithelial cells.

The influenza virus life cycle can be divided into four basic stages: attachment, entry, replication, and egress which are all dependent in part on the host cell itself, such as an infected epithelial cell. Numerous host-cell-dependent factors can affect and control influenza virus attachment and uptake by: (i) proteolytic cleavage of viral HA by host cell-derived serine proteases, (ii) host cell-derived innate immune defense molecules aimed at binding and neutralizing the infectious virions, and (iii) antiviral mediators limiting viral replication and shedding of virus particles. Modification of any or several of these factors by altering expression of Nrf2 could affect susceptibility to infection. Our results demonstrate that increased Nrf2 activity significantly reduces the expression of the viral $H A$ gene as well as influenza virus titers (Fig. 3). To dissect specific points in the virus life cycle that could determine the role Nrf2 gene expression plays in viral susceptibility and/or viral replication, which ultimately dictates viral pathogenesis and outcome, we developed an enzymatic virus-like particle assay that was adapted from previous studies using VLPs to study HIV and Ebola virus entry [39,44,45]. Our data demonstrate that both genetic and pharmacological manipulation of $\mathrm{Nrf2}$ expression significantly affects influenza virus entry (Fig. 6). Suppressed expression of $\mathrm{Nrf2}$ increased influenza virus entry, while increased expression of Nrf2 reduced viral entry, thus protecting the cells from viral infection. This report is the first to identify a mechanism of action for Nrf2 in the context of the influenza virus life cycle.

The mechanisms through which oxidative stress and/or modified expression of Nrf2 alters influenza virus entry are not clear. Based on previous reports, we hypothesize that increased viral entry and subsequent replication seen in cells with reduced Nrf2 expression/ activity are mediated through the activation of host cellular transmembrane proteases. As indicated above, regulated proteolysis is required for the spread/propagation of many human viruses, including human immunodeficiency virus (HIV), Nipah, Ebola, severe acute respiratory syndrome coronavirus (SARS-CoV), metapneumoviruses, and influenza [46-50]. Previous studies have demonstrated the importance of protease-specific cellular proteases/antiproteases involved in influenza infection, which include transmembrane protease serine 2 (TMPRSS2), human airway trypsin-like protease (HAT), and secretory leukocyte proteinase inhibitor (SLIP) [51,52]. The expression of these proteases in the lung is necessary for cleavage of the viral HA surface protein, thus allowing viral fusion and entry into the host cell. Studies have shown a correlation between inflammation and oxidative stress which leads to altered expression of these proteases/antiproteases. Specifically, HAT has been shown to 
be released into the airway fluids under inflammatory conditions, particularly in asthmatics $[53,54]$, and a murine study showed that SLPI gene expression was increased in Nrf2-deficient mice which led to increased inflammation and demonstrated a balance between oxidative stress and protease expression [52]. These studies combined with our data presented here lead us to hypothesize that oxidative stress, which is propagated via decreased Nrf2 gene expression, causes an increase in serine protease activity, culminating in increased efficiency of HA cleavage and thus increased viron entry, which we demonstrated in Fig. 6.

Interestingly, our results demonstrate that supplementation with SFN and to a greater extent EGCG not only increased Nrf2 protein levels but also induced the expression of three well-characterized antiviral response genes which include RIG-I, IFN- $\beta$, and $M x A$ (Fig. 5). It is noteworthy that the increased expression of these antiviral genes was induced via supplementation with EGCG in the absence of a viral infection. It is known that infection and replication of viruses result in the accumulation of intracellular ssRNA and dsRNA in the host cell, which triggers multiple host response mechanisms, including the expression of type I INFs, MxA, and RIG-I. Viral infections normally induce the production of type I IFNs, which in turn activate the synthesis of numerous interferon-stimulated genes (ISGs). ISGs collectively induce an "antiviral state" in the host cell itself as well as the neighboring cells, thus limiting viral replication in these cells. One of these ISGs is MxA, which belongs to a small family of GTPases that have been shown to inhibit viral replication. MxA has also displayed antiviral activity toward influenza A virus [55]. Another IFN-inducible gene is RIG-I, which is a cytosolic DExD/H boxcontaining RNA helicase that interacts with dsRNA and augments interferon production in response to a viral infection [56,57]. We demonstrate that treatment with EGCG, in the absence of a viral infection, increased the mRNA expression levels of RIG-I, which appear to be in contrast to a recent study which showed that EGCG suppresses Rig-I signaling [58]. This study identified, in a small molecule screen, that EGCG binds to RIG-I and reported that at certain concentrations EGCG efficiently binds to RIG-I and, while not interfering with RIG-I's ability to bind RNA, does suppresses RIG-I signaling. However, these studies were performed in the HEK293T cell line, which could contribute to the somewhat conflicting results. Based on our observations, we hypothesize that EGCG up-regulates the expression of these antiviral genes which proactively protects the cells prior to viral infection by inducing and "antiviral protective state." It is possible that IFN- $\beta, R I G-I$, and $M x A$ genes may contain an $\mathrm{Nrf} 2$ binding site in their promoter regions, and the induction of Nrf2 would thus increase the transcription of these antiviral genes. However, at least to our knowledge, essential Nrf2 binding sites have not been identified in promoters of any of the genes listed above and studies examining gene expression profiling of Nrf2 in mice did not report differences in the antiviral or interferon responsive genes $[40,59]$. It is conceivable that the effects of SFN and EGCG on IFN- $\beta$, RIG-I, and $M x A$ expression are Nrf2 independent or that the effects are species and/or cell-type specific.

SFN and EGCG have been shown to have potent antioxidant capacities, in part by inducing the expression of a number of antioxidant enzymes [60]. In vitro and in vivo studies have shown that these supplements potently induce the expression of phase II antioxidant genes, which was associated with Nrf2-electrophile response element (EpRE) signaling [37,61-63]. The mechanism of activation for Nrf2 induction involves serine/threonine phosphorylation, leading to increased nuclear accumulation and binding to the EpRE [64]. Whether and how activation of Nrf2-dependent gene expression is involved in its potential antiviral effects are not known. Our data show that EGCG and to a lesser extent SFN modifies influenza replication in human respiratory epithelial cells at $1 \mu \mathrm{M}$ concentration and that the effects of EGCG on viral replication are abolished in cells with knocked-down Nrf2 expression (Fig. 2). It is likely that higher concentrations of SFN would yield significant effects on viral replication. These observations are similar to previous mouse in vivo studies showing that supplementation with SFN only reduced RSV infection in $\mathrm{Nrf} 2^{+/+}$mice but not $\mathrm{Nrf2} 2^{-/-}$mice [17]. Previous studies have indicated that EGCG directly binds influenza virus and therefore prevents attachment and entry into host cells $[65,66]$. However, these studies were conducted in MDCK cells, which are not a natural host cell for influenza and require addition of exogenous proteases to achieve viral entry [65]. Our data demonstrate that supplementation of differentiated NECs with either SFN or EGCG from the basolateral side (to eliminate direct interaction with the virus during infection) significantly decreases influenza virus entry and replication and that these effects were dependent on Nrf2 (Fig. 4).

Nrf2 status may influence susceptibility to viral exacerbations in specific subpopulations. It has been reported that Nrf2 protects the lung against oxidative stress [20,40], and recent data describe functional polymorphisms within the Nrf2 gene in humans [67]. Nrf2 has been identified as a susceptibility gene that increases the risk of acute lung injury, and other reports have also identified a role for Nrf2 in pulmonary diseases associated with oxidative stress, such as chronic obstructive pulmonary disease (COPD) and asthma $[68,69]$. Viral infections have been shown to exacerbate these diseases. Understanding how Nrf2 orchestrates cellular defense mechanisms may provide insight to the development of novel interventions and preventative strategies targeted against oxidative airway diseases. Investigating antioxidant supplementation treatment along with potential inhibitors of influenza-activating type II transmembrane serine proteases (TTSPs) could be important additions to the current antiviral therapy which includes targeting neuraminidase and the ion channel M2. Influenza infection remains a major global public health concern, and understanding the mechanisms that modulate susceptibility to influenza infection can have vast impacts on morbidity, mortality, and ultimately infection outcome.

In summary, this work provides insight into identifying and understanding new molecular pathways in which Nrf2 gene expression potentially protect cells from viral infection. Our work demonstrates that activation of the Nrf2-dependent gene expression prior to influenza abrogates viral entry and replication. We also found that the transcription factor Nrf2 plays a critical role in dictating susceptibility to viral infection at the level of the epithelium. We have shown that nutritional supplementation, with SFN or EGCG, not only increases Nrf2 levels but also increases the expression of multiple antiviral mediators in the absence of a viral infection. We hypothesize that induction of these antiviral mediators in turn initiates an "antiviral state" priming the cells against a viral infection, thus limiting virus entry and replication. Previous studies have demonstrated that in humans orally administered SFN at doses of $200 \mu \mathrm{mol}$ yields peak plasma levels reaching about $2 \mu \mathrm{mol} / \mathrm{L}$ [70]. Similarly, previous studies determining the pharmacokinetics of EGCG in humans reported that a single dose of $1.5 \mathrm{mmol}$ orally administered EGCG achieved peak plasma concentrations averaging $1.3 \mu \mathrm{mol} / \mathrm{L}$ [71]. Thus, levels of SFN and EGCG shown here to have antiviral effects are clinically feasible. Further studies aimed at using orally administered SFN or EGCG may provide greater insights into potential novel antiviral therapeutic interventions.

\section{Acknowledgments}

We thank Ms. Luisa E. Brighton for her expert technical assistance. We also acknowledge VLP plasmids and technical assistance from Adolfo Garcia-Sastre's laboratory, Mount Sinai School of Medicine. The project described was in part supported by Grant HL095163 from the National Heart, Lung, and Blood Institute (NHLBI), NIH, a grant from the Flight Attendant Medical Research Institute (FAMRI), and a grant from the Environmental Protection Agency (CR829522) (all I.J.).This 
research was also supported by Grant T32 ES007126-26 NIEHS Curriculum of Toxicology Training Grant.

\section{References}

[1] Monto, A. S. Occurrence of respiratory virus: time, place and person. Pediatr. Infect Dis. J. 23:S58-S64; 2004.

[2] Lambert, L. C.; Fauci, A. S. Influenza vaccines for the future. N. Engl. J. Med. 363: 2036-2044; 2010.

[3] Thompson, W. W.; Shay, D. K.; Weintraub, E.; Brammer, L.; Cox, N.; Anderson, L. J.; Fukuda, K. Mortality associated with influenza and respiratory syncytial virus in the United States. JAMA 289:179-186; 2003

[4] Thompson, W. W.; Shay, D. K.; Weintraub, E.; Brammer, L.; Bridges, C. B.; Cox, N. J.; Fukuda, K. Influenza-associated hospitalizations in the United States. JAMA 292: 1333-1340; 2004.

[5] Watanabe, T.; Watanabe, S.; Kawaoka, Y. Cellular networks involved in the influenza virus life cycle. Cell Host Microbe 7:427-439; 2010.

[6] Weycker, D.; Edelsberg, J.; Halloran, M. E.; Longini Jr., I. M.; Nizam, A.; Ciuryla, V.; Oster, G. Population-wide benefits of routine vaccination of children against influenza. Vaccine 23:1284-1293; 2005.

[7] Glezen, W. P. Emerging infections: pandemic influenza. Epidemiol. Rev. 18:64-76; 1996.

[8] Glezen, W. P.; Greenberg, S. B.; Atmar, R. L.; Piedra, P. A.; Couch, R. B. Impact of respiratory virus infections on persons with chronic underlying conditions. JAMA 283:499-505; 2000.

[9] Beck, M. A. Antioxidants and viral infections: host immune response and viral pathogenicity. J. Am. Coll. Nutr. 20:384S-388S discussion 396S-397S; 2001.

[10] Flanigan, C. C.; Sprunt, D. H. The effect of malnutrition on the susceptibility of the host to viral infection. J. Exp. Med. 104:687-706; 1956.

[11] Smith, A. G.; Sheridan, P. A.; Harp, J. B.; Beck, M. A. Diet-induced obese mice have increased mortality and altered immune responses when infected with influenza virus. J. Nutr. 137:1236-1243; 2007.

[12] Graham, M. B.; Braciale, T. J. Resistance to and recovery from lethal influenza virus infection in B lymphocyte-deficient mice. J. Exp. Med. 186:2063-2068; 1997.

[13] Toapanta, F. R.; Ross, T. M. Impaired immune responses in the lungs of aged mice following influenza infection. Respir. Res. 10:112; 2009.

[14] Noah, T. L.; Zhou, H.; Monaco, J.; Horvath, K.; Herbst, M.; Jaspers, I. Tobacco smoke exposure and altered nasal responses to live attenuated influenza virus. Environ. Health Perspect. 119 (1):78-83; 2011.

[15] Jaspers, I.; Ciencewicki, J. M.; Zhang, W.; Brighton, L. E.; Carson, J. L.; Beck, M. A.; Madden, M. C. Diesel exhaust enhances influenza virus infections in respiratory epithelial cells. Toxicol. Sci. 85:990-1002; 2005.

[16] Jaspers, I.; Horvath, K. M.; Zhang, W.; Brighton, L. E.; Carson, J. L.; Noah, T. L. Reduced expression of IRF7 in nasal epithelial cells from smokers after infection with influenza. Am. J. Respir. Cell Mol. Biol. 43:368-375; 2009.

[17] Cho, H. Y.; Imani, F.; Miller-DeGraff, L.; Walters, D.; Melendi, G. A.; Yamamoto, M.; Polack, F. P.; Kleeberger, S. R. Antiviral activity of Nrf2 in a murine model of respiratory syncytial virus disease. Am. J. Respir. Crit. Care Med. 179:138-150 2009.

[18] Jakab, G. J.; Bassett, D. J. Influenza virus infection, ozone exposure, and fibrogenesis. Am. Rev. Respir. Dis. 141:1307-1315; 1990.

[19] Razani-Boroujerdi, S.; Singh, S. P.; Knall, C.; Hahn, F. F.; Pena-Philippides, J. C. Kalra, R.; Langley, R. J.; Sopori, M. L. Chronic nicotine inhibits inflammation and promotes influenza infection. Cell. Immunol. 230:1-9; 2004.

[20] Cho, H. Y.; Kleeberger, S. R. Nrf2 protects against airway disorders. Toxicol. Appl. Pharmacol. 244:43-56; 2010.

[21] Kim, Y. H.; Coon, A.; Baker, A. F.; Powis, G. Antitumor agent PX-12 inhibits HIF-1alpha protein levels through an Nrf2/PMF-1-mediated increase in spermidine/spermine acetyl transferase. Cancer Chemother. Pharmacol., doi:10.1007/s00280-010-1500-0. 2010.

[22] Rahman, I. Antioxidant therapeutic advances in COPD. Ther. Adv. Respir. Dis. 2: $351-374 ; 2008$

[23] Jia, D.; Rahbar, R.; Chan, R. W.; Lee, S. M.; Chan, M. C.; Wang, B. X.; Baker, D. P.; Sun, B.; Peiris, J. S.; Nicholls, J. M.; Fish, E. N. Influenza virus non-structural protein 1 (NS1) disrupts interferon signaling. PLoS One 5:e13927; 2010.

[24] Chen, S.; Short, J. A.; Young, D. F.; Killip, M. J.; Schneider, M.; Goodbourn, S Randall, R. E. Heterocellular induction of interferon by negative-sense RNA viruses. Virology 407:247-255; 2010

[25] Jia, D.; Rahbar, R.; Chan, R. W.; Lee, S. M.; Chan, M. C.; Wang, B. X.; Baker, D. P.; Sun, B.; Peiris, J. S.; Nicholls, J. M.; Fish, E. N. Influenza virus non-structural protein 1 (NS1) disrupts interferon signaling. PLoS One 5:e13927; 2010.

[26] Haller, O.; Kochs, G. Interferon-induced mx proteins: dynamin-like GTPases with antiviral activity. Traffic 3:710-717; 2002.

[27] Zhou, H.; Wang, X.; Brighton, L.; Hazucha, M.; Jaspers, I.; Carson, J. L. Increased nasal epithelial ciliary beat frequency associated with lifestyle tobacco smoke exposure. Inhal. Toxicol. 21:875-881; 2009.

[28] Reddel, R. R.; Ke, Y.; Gerwin, B. I.; McMenamin, M. G.; Lechner, J. F.; Su, R. T.; Brash, D. E.; Park, J. B.; Rhim, J. S.; Harris, C. C. Transformation of human bronchial epithelial cells by infection with SV40 or adenovirus-12 SV40 hybrid virus, or transfection via strontium phosphate coprecipitation with a plasmid containing SV40 early region genes. Cancer Res. 48:1904-1909; 1988.

[29] Niwa, H.; Yamamura, K.; Miyazaki, J. Efficient selection for high-expression transfectants with a novel eukaryotic vector. Gene 108:193-199; 1991.
[30] Quinlivan, M.; Zamarin, D.; Garcia-Sastre, A.; Cullinane, A.; Chambers, T.; Palese, P. Attenuation of equine influenza viruses through truncations of the NS1 protein. J. Virol. 79:8431-8439; 2005.

[31] Neumann, G.; Watanabe, T.; Ito, H.; Watanabe, S.; Goto, H.; Gao, P.; Hughes, M.; Perez, D. R: Donis, R. Hoffmann, E., et al. Generation of influenza A viruses entirely from cloned cDNAs. Proc. Natl Acad. Sci. U. S. A. 96:9345-9350; 1999.

[32] Manicassamy, B.; Rong, L. Expression of Ebolavirus glycoprotein on the target cells enhances viral entry. Virol. J. 6:75; 2009.

[33] Marsh, G. A.; Hatami, R.; Palese, P. Specific residues of the influenza A virus hemagglutinin viral RNA are important for efficient packaging into budding virions. J. Virol. 81:9727-9736; 2007.

[34] Jaspers, I.; Zhang, W.; Brighton, L. E.; Carson, J. L.; Styblo, M.; Beck, M. A. Selenium deficiency alters epithelial cell morphology and responses to influenza. Free Radic Biol. Med. 42:1826-1837; 2007.

[35] Farag-Mahmod, F. I.; Wyde, P. R.; Rosborough, J. P.; Six, H. R. Immunogenicity and efficacy of orally administered inactivated influenza virus vaccine in mice. Vaccine 6:262-268; 1988

36] Nguyen, T.; Sherratt, P. J.; Huang, H. C.; Yang, C. S.; Pickett, C. B. Increased protein stability as a mechanism that enhances Nrf2-mediated transcriptional activation of the antioxidant response element. Degradation of Nrf2 by the $26 \mathrm{~S}$ proteasome. J. Biol. Chem. 278:4536-4541; 2003.

[37] Nair, S.; Barve, A.; Khor, T. O.; Shen, G. X.; Lin, W.; Chan, J. Y.; Cai, L.; Kong, A. N. Regulation of Nrf2- and AP-1-mediated gene expression by epigallocatechin-3gallate and sulforaphane in prostate of Nrf2-knockout or C57BL/6J mice and PC-3 AP-1 human prostate cancer cells. Acta Pharmacol. Sin. 31:1223-1240; 2010.

[38] Shinkai, Y.; Sumi, D.; Fukami, I.; Ishii, T.; Kumagai, Y. Sulforaphane, an activator of $\mathrm{Nrf} 2$, suppresses cellular accumulation of arsenic and its cytotoxicity in primary mouse hepatocytes. FEBS Lett. 580:1771-1774; 2006.

[39] Tscherne, D. M.; Manicassamy, B.; Garcia-Sastre, A. An enzymatic virus-like particle assay for sensitive detection of virus entry. J. Virol. Methods 163:336-343; 2010.

[40] Cho, H. Y.; Reddy, S. P.; Kleeberger, S. R. Nrf2 defends the lung from oxidative stress. Antioxid. Redox Signal. 8:76-87; 2006.

[41] Zhang, K.; Yang, H.; Wang, Y.; Ma, L.; Zhou, Q. Expression and significance of nrf2 and its target genes in pulmonary adenocarcinoma a549 cells resistant to cisplatin. Zhongguo Fei Ai Za Zhi 12:1150-1154; 2009.

[42] Florczyk, U.; Loboda, A.; Stachurska, A.; Jozkowicz, A.; Dulak, J. Role of Nrf2 transcription factor in cellular response to oxidative stress. Postepy Biochem. 56: 147-155; 2010

43] Robbins, C. S.; Bauer, C. M.; Vujicic, N.; Gaschler, G. J.; Lichty, B. D.; Brown, E. G.; Stampfli, M. R. Cigarette smoke impacts immune inflammatory responses to influenza in mice. Am. J. Respir. Crit. Care Med. 174:1342-1351; 2006.

[44] Cavrois, M.; De Noronha, C.; Greene, W. C. A sensitive and specific enzyme-based assay detecting HIV-1 virion fusion in primary T lymphocytes. Nat. Biotechnol. 20: 1151-1154; 2002

[45] Yonezawa, A.; Cavrois, M.; Greene, W. C. Studies of ebola virus glycoproteinmediated entry and fusion by using pseudotyped human immunodeficiency virus type 1 virions: involvement of cytoskeletal proteins and enhancement by tumor necrosis factor alpha. J. Virol. 79:918-926; 2005.

[46] Shulla, A.; Heald-Sargent, T.; Subramanya, G.; Zhao, J.; Perlman, S.; Gallagher, T. A transmembrane serine protease is linked to the severe acute respiratory syndrome coronavirus receptor and activates virus entry. J. Virol. 85:873-882; 2011.

[47] Matsuyama, S.; Nagata, N.; Shirato, K.; Kawase, M.; Takeda, M.; Taguchi, F. Efficient activation of the severe acute respiratory syndrome coronavirus spike protein by the transmembrane protease TMPRSS2. J. Virol. 84:12658-12664; 2010.

[48] Chandran, K.; Sullivan, N. J.; Felbor, U.; Whelan, S. P.; Cunningham, J. M. Endosomal proteolysis of the Ebola virus glycoprotein is necessary for infection. Science 308:1643-1645; 2005.

[49] Matsuyama, S.; Taguchi, F. Two-step conformational changes in a coronavirus envelope glycoprotein mediated by receptor binding and proteolysis. J. Virol. 83: 11133-11141; 2009

[50] Simmons, G.; Reeves, J. D.; Rennekamp, A. J.; Amberg, S. M.; Piefer, A. J.; Bates, P. Characterization of severe acute respiratory syndrome-associated coronavirus (SARS-CoV) spike glycoprotein-mediated viral entry. Proc. Natl Acad. Sci. U. S. A 101:4240-4245; 2004

[51] Bottcher, E.; Matrosovich, T.; Beyerle, M.; Klenk, H. D.; Garten, W.; Matrosovich, M. Proteolytic activation of influenza viruses by serine proteases TMPRSS2 and HAT from human airway epithelium. J. Virol. 80:9896-9898; 2006.

[52] Iizuka, T.; Ishii, Y.; Itoh, K.; Kiwamoto, T.; Kimura, T.; Matsuno, Y.; Morishima, Y.; Hegab, A. E.; Homma, S.; Nomura, A., et al. Nrf2-deficient mice are highly susceptible to cigarette smoke-induced emphysema. Genes Cells 10:1113-1125; 2005.

[53] Yasuoka, S.; Ohnishi, T.; Kawano, S.; Tsuchihashi, S.; Ogawara, M.; Masuda, K: Yamaoka, K.; Takahashi, M.; Sano, T. Purification, characterization, and localization of a novel trypsin-like protease found in the human airway. Am. J. Respir. Cell Mol. Biol. 16:300-308; 1997.

[54] Szabo, R.; Bugge, T. H. Type II transmembrane serine proteases in development and disease. Int. J. Biochem. Cell Biol. 40:1297-1316; 2008.

[55] Pavlovic, J.; Zurcher, T.; Haller, O.; Staeheli, P. Resistance to influenza virus and vesicular stomatitis virus conferred by expression of human MxA protein. J. Virol. 64:3370-3375; 1990

[56] Schlee, M.; Hartmann, G. The chase for the RIG-I ligand-recent advances. Mol. Ther. 18:1254-1262; 2010.

[57] Yoneyama, M.; Kikuchi, M.; Natsukawa, T.; Shinobu, N.; Imaizumi, T.; Miyagishi, M.; Taira, K.; Akira, S.; Fujita, T. The RNA helicase RIG-I has an essential function in double-stranded RNA-induced innate antiviral responses. Nat. Immunol. 5:730-737; 2004. 
[58] Ranjith-Kumar, C. T.; Lai, Y.; Sarisky, R. T.; Cheng Kao, C. Green tea catechin, epigallocatechin gallate, suppresses signaling by the dsRNA innate immune receptor RIG-I. PLoS One 5 e12878; 2010.

[59] Cho, H. Y.; Reddy, S. P.; Debiase, A.; Yamamoto, M.; Kleeberger, S. R. Gene expression profiling of NRF2-mediated protection against oxidative injury. Free Radic. Biol. Med. 38:325-343; 2005.

[60] Na, H. K.; Kim, E. H.; Jung, J. H.; Lee, H. H.; Hyun, J. W.; Surh, Y. J. (-)Epigallocatechin gallate induces Nrf2-mediated antioxidant enzyme expression via activation of PI3K and ERK in human mammary epithelial cells. Arch. Biochem. Biophys. 476:171-177; 2008.

61] Guerrero-Beltran, C. E.; Calderon-Oliver, M.; Pedraza-Chaverri, J.; Chirino, Y. Protective effect of sulforaphane against oxidative stress: recent advances. Exp. Toxicol. Pathol., doi:10.1016/j.etp.2010.11.005; 2010.

[62] Wan, S. B.; Landis-Piwowar, K. R.; Kuhn, D. J.; Chen, D.; Dou, Q. P.; Chan, T. H. Structure-activity study of epi-gallocatechin gallate (EGCG) analogs as proteasome inhibitors. Bioorg. Med. Chem. 13:2177-2185; 2005

[63] Zhu, M.; Chen, Y.; Li, R. C. Oral absorption and bioavailability of tea catechins. Planta Med. 66:444-447: 2000.

[64] Wu, C. C.; Hsu, M. C.; Hsieh, C. W.; Lin, J. B.; Lai, P. H.; Wung, B. S. Upregulation of heme oxygenase- 1 by epigallocatechin-3-gallate via the phosphatidylinositol 3-kinase/Akt and ERK pathways. Life Sci. 78:2889-2897; 2006.
[65] Nakayama, M.; Suzuki, K.; Toda, M.; Okubo, S.; Hara, Y.; Shimamura, T. Inhibition of the infectivity of influenza virus by tea polyphenols. Antiviral Res. 21:289-299; 1993.

[66] Song, J. -M.; Lee, K. -H.; Seong, B. -L. Antiviral effect of catechins in green tea on influenza virus. Antiviral Res. 68:66-74; 2005.

[67] Marzec, J. M.; Christie, J. D.; Reddy, S. P.; Jedlicka, A. E.; Vuong, H.; Lanken, P. N.; Aplenc, R.; Yamamoto, T.; Yamamoto, M.; Cho, H. Y.; Kleeberger, S. R. Functional polymorphisms in the transcription factor NRF2 in humans increase the risk of acute lung injury. FASEB J. 21:2237-2246; 2007.

[68] Repine, J. E. Scientific perspectives on adult respiratory distress syndrome. Lancet 339:466-469; 1992.

[69] Hernandez, M. L.; Lay, J. C.; Harris, B.; Esther Jr., C. R.; Brickey, W. J.; Bromberg, P. A.; Diaz-Sanchez, D.; Devlin, R. B.; Kleeberger, S. R.; Alexis, N. E.; Peden, D. B. Atopic asthmatic subjects but not atopic subjects without asthma have enhanced inflammatory response to ozone. J. Allergy Clin. Immunol. 126 537-544 e531; 2010.

[70] Ye, L: Dinkova-Kostova, A. T: Wade, K. L. Zhang, Y: Shapiro, T. A. Talalay, P. Quantitative determination of dithiocarbamates in human plasma, serum, erythrocytes and urine: pharmacokinetics of broccoli sprout isothiocyanates in humans. Clin. Chim. Acta 316:43-53; 2002.

[71] Van Amelsvoort, J. M.; Van Hof, K. H.; Mathot, J. N.; Mulder, T. P.; Wiersma, A.; Tijburg, L. B. Plasma concentrations of individual tea catechins after a single oral dose in humans. Xenobiotica 31:891-901; 2001 